\title{
Progress on Intervention and Mobilization for Global Food Security
}

\author{
Albert E J McGill \\ James Martin Institute for Science and Civilization, Said Business School, \\ Oxford University, Park End Street, OXFORD, OX1 1HP, United Kingdom. \\ albert.mcgill@sbs.ox.ac.uk
}

\section{KEYWORDS}

Food security, Hunger, Nutrition, Food science

\begin{abstract}
.
In recent times, there have been a number of expressions of concern, particularly at Congresses, at the paucity of reported action by the Adhering Bodies of IUFoST and all food professionals, in responding to the Budapest Declaration of 1995. These have been voiced with considerable passion, in forthright presentations by Owen Fennema in Seoul (IUFoST, 2001), Ismael Serageldin in Chicago (IUFoST, 2003) and in a "call to arms" in the Newsletter by the President, Alan Mortimer.

One response has been the development of a proposal to run a project aimed at using readily available data on the State of Food Insecurity in the World (FAO, 2004; 2005), and seeking to encourage each Adhering Body to consider if the data for their own country was accurate and sufficiently detailed for them to undertake minor activities to bridge the gap between what was already being done, by FAO and others, and what was needed to address food insecurity at home, hence the concept of mobilization. The role of the project manager was to record and encourage activity, and support areas with identified lack of resources, where possible, hence intervention.
\end{abstract}

The project was endorsed by the Governing Council of IUFoST in March, 2005, and this paper records the progress of the project so far.

\section{INTRODUCTION}

The Budapest Declaration's key points emphasize the delegates' "..determination to work for the elimination of hunger and the reduction of all forms of malnutrition throughout the world...ensure sustained nutritional well-being for all people in a peaceful, just and environmentally safe world...recognizing that access to nutritionally adequate and safe food is the right of each individual." Whilst this seems overwhelming and unattainable, the idea of not attempting to tackle hunger on an international scale, but rather to break it down into local components that might be influenced by the voluntary work of individual professionals, "the new abolitionists" in Serageldin's words, seemed more feasible. It would require the coordination of the Adhering Bodies and collaboration with existing work of the major agencies such as FAO/WHO/WFP and other groups like OXFAM. How could this be achieved?

\section{METHODOLOGY}

Mobilizing the Profession. The optimal way to involve the largest number of qualified food professionals on any project is to use the organizational structure of IUFoST and its Adhering Bodies (ABs). This requires the authority and approval of the Governing Council (GC) and the support of the secretariat. A proposal was put to the GC at its meeting in Kuala Lumpur in March, 2005.

Definitions. Although the initial focus and concerns were on world hunger, the terms food security/insecurity are considered more appropriate and parallel the approach of the major food agencies: "Food Security exists when all people, at all times, have physical access to sufficient, safe and nutritious food to meet their dietary needs and food preference for an active and healthy life. "(FAO, 1996). 
Communications. The apparent lack of progress on the Declaration as reported by Fennema and Serageldin presupposed that a survey of such activities had been carried out and/or some record had been kept. Apart from the draft outline report from Joseph Hulse as Chair of an Integrated Food Systems Task Force, no evidence of any relevant action could be found. A more robust system of communication and record of this project would be required. Complementary Programmes. Both the size and technical focus of IUFoST and the professions accommodated within its ABs, limit the inputs and impact that can be directed onto the issue of Global Food Security. Complementing the work of the major players, FAO, WHO, WFP, and the voluntary agencies, such as OXFAM, will be likely to make the greatest impact.

\section{RESULTS}

Mobilizing the Profession. At its meeting in Kuala Lumpur in March, 2005, the Governing Council endorsed the proposed project and undertook to advise the Adhering Bodies that the project should be supported.

Definitions. The use of the terms food security/insecurity has made the identification of existing and complementary programmes more effective.

Communications. Contact with the IUFoST secretariat has been effective but has highlighted how little hard information exists on the composition of many ABs with respect to the professions they contain within their representation. No attempts have been made to clarify this until a clear plan has been formulated and a clear message can be sent.

Complementary Programmes. FAO provide the major source of programmes starting with the Special Programme on Food Security (SPFS) (FAO, 2005a), and moving on to their mapping system (FIVIMS, 2005). The International Food Policy Research Institute have prepared a number of papers for the Hunger Task Force and the Millennium Project, but their five year plan pays little attention to processes that convert crops to food (IFPRI, 2005). The International Council for Science (ICSU) of which IUFoST is a member, has supported the Global Environmental Change and Food Systems project (GECAFS, 2005), but has discounted any input from IUFoST. More details are available in a recent paper presented in Oslo (McGill, 2006b).

\section{CONCLUSIONS}

The Budapest Declaration (IUFoST, 1995) has strength of pledge but no specific stages, timelines or deliverables. Communications with the ABs are not yet responsive nor synchronized. The content and range of existing programmes on Food Security have not been appreciated by IUFoST nor have other agencies taken much account of food science/technology professionals in developing their projects. Much of this appears to be from ignorance or oversight rather than deliberate exclusion. This project should continue if the ethical stance of IUFoST is not to be undermined through failure to honour their own Declaration.

\section{REFERENCES}

The literature cited in this paper may be found, together with an extended text, at the following site. Any difficulties or need for explanation may be obtained from the author. McGill, A E J, (2006b). "Technological interventions for global food security", in Kaiser, M \& Lien, M, (eds.) "Ethics and the politics of food", EurSAFE 2006, Oslo, Norway, 22-24 June, Wageningen Academic Publishers, ISBN-10: 90-8686-008-7; ISBN-13: 978-90-8686-008-1; Pp 363-367. 